\title{
THE INFLUENCE OF TRANSPORT PHENOMENA ON THE FLUIDIZED BED COMBUSTION OF A SINGLE CARBON PARTICLE
}

\author{
W. Prins and W.P.M. van Swaaij \\ University of Twente, Chem. Eng. Dept., PO Box 217, 7500 AE Enschede, The Netherlands
}

\begin{abstract}
The burning rate and temperature of the carbon particles are known to affect the efficiency of a fluidized bed combustor, and also the emission levels of undesired noxious components. The main results of an extensive study on the fluidized bed combustion behaviour of a single carbon particle [1] are summarized. Calculations have been carried out with a newly developed transient model, the ASPC model, and also with the much simpler progressive conversion model. Besides, many experiments have been performed in a lab-scale fluid bed construction to measure the burning rate and temperature of individual carbon particles for various conditions. From the comparison between experimental results and model predictions it has been overall concluded that the ASPC model is especially useful in i) describing the complex behaviour of progressive carbon conversion for the regime of combustion controlled by carbon reactivity plus intraparticle oxygen diffusion, and ii) estimating the conditions for which transition to the regime of external mass and heat transfer control occurs. Accurate prediction of the carbon particle burning rate and temperature is only possible for the latter combustion regime.
\end{abstract}

\section{SCOPE, CONDITIONS}

Graphite spheres (density: $1780 \mathrm{~kg} / \mathrm{m}^{3}$ ) are used as a fuel material. In contrast with coal-derived chars, graphite is a well-defined and uniform material for which combustion experiments yield accurate and reproducible results. The ASPC model is applicable over the entire range of combustion conditions, and basically for all types of carbon. Validation of the model with a limited number of experiments however, is achieved especially by the use of graphite particles. While for certain extreme combustion conditions much simpler models may be used ("shrinking core model", "progressive conversion model"), the ASPC model also allows to estimate possible errors/deviations introduced by the simplifications. This study on the combustion of graphite spheres further shows, in theory and practice, the specific features of pore diffusion limited combustion, thereby facilitating recognition and proper appreciation of similar features in coal-derived char combustion. Extension of the ASPC model calculations to the combustion of "real" char particles is quite well possible, and subject of future work. It should be noticed however that numerical results are always limited to the specific char type considered. Wide variations in reactivity and structural properties do not allow a generalized approach in this respect.

Conditions of the model calculations are linked-up to those of the laboratory tests (see Table 1). Coefficients for mass and heat exchange between the burning sphere and the fluidized bed are derived from the empirical correlations of Ref. [2,3]. Graphite's reactivity has been determined by thermobalance experiments for pulverized particles. The variables of these kinetic experiments were: i) particle size fraction, ii) temperature $T$, and iii) gas phase oxygen concentration $c$. As a result the following expression was derived for the reaction rate on actual mass basis: 
$R_{m}=\left[1.3 \times 10^{7} \exp \left(-1.66 \times 10^{5} / \mathrm{RT}\right)\right] c$

$(\mathrm{kg} / \mathrm{kg} \mathrm{s})$

A number of the fluidized bed combustion experiments have been carried out for graphite spheres connected to a thermocouple, to yield simultaneously the burning sphere excess-temperature $\Delta T$.

\section{MODELS}

Calculated results have been obtained while regarding the following assumptions: a) spherical symmetry, b) isothermic and c) isobaric conditions inside the particle, d) use of constant binary diffusion coefficents, e) neglect of the gasification reaction: $\mathrm{C}+\mathrm{CO}_{2}-->2 \mathrm{CO}, \mathrm{f}$ ) the combustion reaction $(1+n) \mathrm{C}+(1+n / 2) \mathrm{O}_{2}--->\mathrm{nCO}+\mathrm{CO}_{2}$ is first order in oxygen, $\left.\mathrm{g}\right)$ neglect of $\mathrm{CO}$-oxidation in or near the burning particle, $h$ ) neglect of a radiative contribution with the heat transferred to the fluidized bed.

Two models have been used for the computations. The first one is the well-known progressive conversion model usually applied for catalyst particles [4]. It relies on solution of the intraparticle oxygen mass balance for a single steady-state situation which in the present case has been chosen as the one of a just fully developed reaction zone (maximum combustion rate) with fixed and averaged values for the carbon density $\left(1000 \mathrm{~kg} / \mathrm{m}^{3}\right)$ or porosity $(0.5)$, the effective diffusivity $(0.05 \mathrm{D}$ $\left.\mathrm{m}^{2} / \mathrm{s}\right)$, and the volumetric reaction rate $\left(\mathrm{R}_{\mathrm{y}}=(\rho / \Lambda) \mathrm{R}_{\mathrm{m}}\left(\mathrm{kgO}_{2} / \mathrm{m}^{3} \mathrm{~s}\right)\right)$.

The second model, called the ASPC model, is based on the Dusty Gas flux equations [5] for mass transport through porous media and allows computation of concentrations and mole fluxes of the various involved gaseous components as a function of the radial position inside the carbon particle. (Bliek [6] applied a similar model for coal particle gasification.) A local-conversion dependent effective diffusivity and reactivity are introduced now; these parameters will therefore be a function of the radial coördinate. The model also accounts for possible pressure gradients inside the particle. It has further been up-graded by supplying a dynamic part to describe the transient effect of the local degree of conversion.

In both models, the rate of external mass transport has been introduced by a boundary condition which sets the flux of oxygen at the particle's external surface equal to $\mathrm{k}_{\mathrm{d}}\left(\mathrm{c}_{\infty}-\mathrm{c}_{\mathrm{s}}\right) \mathrm{kgO}_{2} / \mathrm{m}^{2} \mathrm{~s}$. Besides, a simple heat balance with both models, stating that the heat produced by the combustion reaction equals the heat transferred to the fluidized bed $\mathrm{h}\left(\mathrm{T}-\mathrm{T}_{\mathrm{b}}\right) \mathrm{Wm}^{-2}$, allows the calculation of the difference between the burning temperature of the particle and the bulk temperature of the bed. For detailed model formulations and the required input data, reference is made to Prins' thesis [1].

The strength of the ASPC model is in its fundamental description of the internal mass transport processes and, secondly, in its capacity to predict the conversion-time behaviour of the burning carbon particle. The progressive conversion model however is much simpler; no numerical procedures are required and, consequently, calculation times are short.

\section{COMPUTATIONAL RESULTS}

Together with values for the combustion rate and the particle burning temperature, progressive conversion model calculations also yield values for the external-surface oxygen concentration $c_{s}$ and the effectiveness factor $\eta$, representing the degree to which the particle's volume is utilized for the heterogeneous combustion reaction. These calculations illustrate the transition of combustion controlled by the kinetics of the heterogeneous reaction ( regime I: $c_{s}=c_{\infty}, \eta=1$ ) to combustion controlled by the external mass transfer rate ( regime III: $c_{s}=0, \eta=0$ ). Regime III combustion is favoured by large carbon particle sizes and high (burning) temperatures. The intermediate regime is characterized by effects of internal mass transport (pore diffusion limitations). Such effects can be observed over a wide particle size range, viz. from $d=0.2$ to $12.8 \mathrm{~mm}$ at $T_{b}=1110 \mathrm{~K}$. In Figures 1 and 2 the transition of combustion regimes can be recognized from the change in effect of the carbon particle diameter on the combustion rate $R$ and on the burning particle excess-temperature $\Delta T$. The extreme situations are: i) regime I: $R \propto \mathrm{d}^{3}, \Delta \mathrm{T} \propto \mathrm{d}^{1.3}$, ii) regime III: $\mathrm{R} \propto \mathrm{d}^{1.5}, \Delta \mathrm{T} \propto \mathrm{d}^{-0.2}$. Obviously, a maximum occurs in the $\Delta \mathrm{T}$ versus d curve while passing through regime II (pore diffusion limitations). Figure 2 shows that, at $T_{b}=1110 \mathrm{~K}$, this maximum is reached around $d=2 \mathrm{~mm}$. 
TABLE 1. Condision of the preacent thidized bed experiment.

\begin{tabular}{|c|c|}
\hline Ded height & $115 \mathrm{~mm}$ \\
\hline bed dinmeter & $100 \mathrm{~mm}$ \\
\hline bed matertul & aloming perticled \\
\hline denaty of bed particleat & $33900 \mathrm{~kg} / \mathrm{m}^{3}$ \\
\hline Iverage bed particle dimmever & $600 \mu \mathrm{m}$ \\
\hline oupericial ges vedocity & $0.46 \mathrm{mis}$ \\
\hline minitmand fouldization veloetily & $0.23 \mathrm{~m} / \mathrm{h}$ \\
\hline bed porosity at minimum Aubdirenton cooditione & 0.42 \\
\hline fuel type & $\begin{array}{l}\text { griphite ( Le Curtoos } \\
\text { Lomine) }\end{array}$ \\
\hline tritial graphtor aphere dimmeters & $3,5,7,9,11,13 \mathrm{~mm}$ \\
\hline Anidized bed tempentares & $985,1110 \mathrm{~K}$ \\
\hline axy gen coocentrubion in the Auditizing gen & $20 \mathrm{mots}$ \\
\hline
\end{tabular}

TABIL 2. Result of ASPC model calcolatione for the cambation of state graphit:

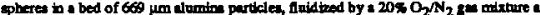
two different bed temperatures. Curboodioxide ts nesumed to be the only primery combustion product $(\Lambda-0.375)$

\begin{tabular}{ccccc}
\hline $\begin{array}{l}T_{b} \\
(K)\end{array}$ & $\begin{array}{c}d_{0} \\
(\operatorname{mm})\end{array}$ & $\begin{array}{c}10^{9} \times R_{\max } \\
(\mathrm{Kg} / \mathrm{n})\end{array}$ & $\begin{array}{c}\left(\Delta \mathrm{T}_{\operatorname{mix}}\right. \\
(\mathrm{K})\end{array}$ & $\begin{array}{c}\tau \\
(\mathrm{min})\end{array}$ \\
\hline 985 & 0.2 & 0.0102 & 2.4 & 19.7 \\
& 0.8 & 0.547 & 10.7 & 20.2 \\
& 3.2 & 18.18 & 28.7 & 33.0 \\
& 12.8 & 324.5 & 41.9 & 131.8 \\
1110 & 0.2 & 0.0858 & 18.8 & 2.15 \\
& 0.8 & 4.399 & 78.5 & 2.32 \\
& 3.2 & 62.86 & 101.8 & 9.93 \\
& 12.8 & 637.7 & 85.0 & 66.95 \\
\hline
\end{tabular}

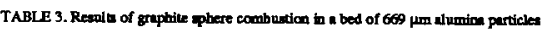

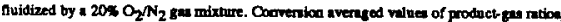

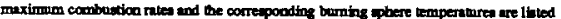

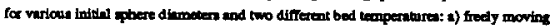
apheres, b) apheres comected to a thermocouple.

\begin{tabular}{|c|c|c|c|c|c|}
\hline & $\begin{array}{l}\mathrm{T}_{\mathrm{b}} \\
(\mathrm{K})\end{array}$ & $\underset{(\mathbf{m m})}{d_{0}}$ & $\mathrm{CovCO}_{2}$ & $\begin{array}{c}10^{7} \times R_{\max } \\
(\mathbf{k q} /(1))\end{array}$ & $\begin{array}{l}\left(\Delta T_{\max }\right. \\
(\mathbf{K})\end{array}$ \\
\hline \multirow[t]{12}{*}{ *) } & 1110 & 3.12 & 0.36 & 1.38 & \\
\hline & & 5.69 & 0.26 & 2.92 & \\
\hline & & 7.24 & 0.25 & 4.69 & \\
\hline & & 9.17 & 0.24 & 6.88 & \\
\hline & & 10.96 & 0.25 & 9.43 & \\
\hline & & 12.80 & 0.32 & 12.37 & \\
\hline & 985 & 3.12 & 0.38 & 0.060 & \\
\hline & & 5.12 & 0.42 & 0.232 & \\
\hline & & 7.15 & 0.37 & 0.678 & \\
\hline & & 9.13 & 0.29 & 1.40 & \\
\hline & & 10.85 & 0.29 & 1.85 & \\
\hline & & 12.85 & 0.43 & 2.43 & \\
\hline \multirow[t]{10}{*}{ b) } & 1110 & 5.06 & 0.35 & 5.14 & 240 \\
\hline & & 7.16 & 0.42 & 6.04 & 197 \\
\hline & & 9.08 & 0.17 & 7.46 & 137 \\
\hline & & 11.12 & 0.26 & 13.7 & 163 \\
\hline & & 13.04 & 0.50 & 13.20 & 137 \\
\hline & 985 & 5.03 & 0.46 & 0.265 & 14 \\
\hline & & 7.20 & 0.35 & 0.605 & 24 \\
\hline & & 9.18 & 0.32 & 1.15 & 26 \\
\hline & & 11.06 & 0.26 & 2.08 & 38 \\
\hline & & 13.13 & 0.44 & 1.94 & 20 \\
\hline
\end{tabular}
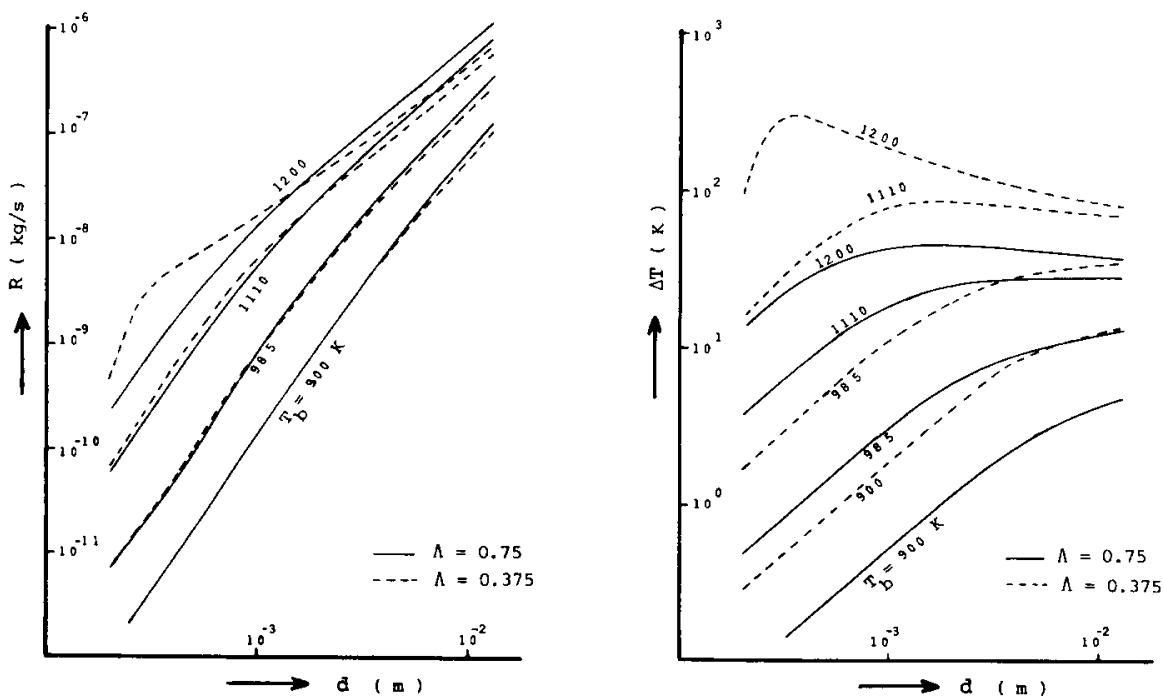

FIGURE 1,2. Combustion rate $R$ and excess-temperature $\Delta T$ of single graphite spheres, buming in a bed of $669 \mu \mathrm{m}$ alumina particles which is fluidized by a $20 \% \mathrm{O}_{2} / \mathrm{N}_{2}$ gas mixture, as a function of their initial diameter. Results of progressive conversion model calculations for various bed temperatures and the two extreme cases of $i)$ primary production of CO only $(\Lambda=0.75)$ and ii) primary production of $\mathrm{CO}_{2}$ only $(\Lambda=0.375)$. 
Figures 1 and 2 also demonstrate the important effect of the ratio of primary combustion products. If $\mathrm{CO}_{2}$ is the only product ( $\mathrm{n}=0, \Lambda=0.375$ ), overtemperatures $\Delta \mathrm{T}$ of burning carbon particles are 2 to 3 times higher than in case only $\mathrm{CO}$ is produced. This results in higher combustion rates for regime I conditions, when the particle temperature effect prevails, but in lower combustion rates for regime III conditions, when the effect of the reaction stoichiommetry is dominant.

The ASPC model allows prediction of the conversion-time behaviour. Figure 3 shows intraparticle profiles of the oxygen and the carbon concentration, calculated for various values of the overall particle conversion degree $\mathbf{X}$. Steep gradients in these profiles, a low external-surface oxygen concentration value and, finally, a continuous decrease of the particle radius alltogether indicate external mass transfer controlled conditions. The reverse phenomena refer to control by the reaction kinetics. As a basic result, these type of concentration diagrams provide the required information to derive, for instance, plots of the average particle density, or of the combustion rate, versus the particle conversion degree.

Figure $4^{\mathrm{a}}$ shows the curves of $R$ versus $X$ to pass through a maximum. An early maximum occurs for regime I and III conditions. However, when the combustion is strongly affected by pore diffusional effects, the maximum is found at relatively large values of $X$ (up to approximately $X=0.45$ ).

As long as the particle diameter remains constant during combustion, $\Delta T$ versus $X$ curves are similar to the $R$ versus $X$ curves (Figure $4^{b}$ ). Both curves develop differently however, from the moment the diameter starts to diminish, viz. according to $\Delta T / R \propto \mathrm{d}^{-1.7}$ in case of regime III conditions. Together with the values of $R_{\max }$ and $\Delta T_{\max }$, burnout times calculated from the ASPC model for the various initial carbon particle diameters, are given in Table 2. For regime I conditions, burnout times are independent of $d$. But they increase with $\mathrm{d}$ for internal and/or external mass transfer controlled conditions. Regime III conditions would eventually lead to $\tau \propto d^{1.5}$

Calculated maximum values for the carbon particle combustion rate and its corresponding excess-temperature (Table 2) are in good agreement with those obtained from the progressive conversion model. The ASPC model predicts somewhat higher values, but the difference is usually smaller than $20 \%$

\section{EXPERIMENTAL RESULTS}

The combustion of millimeter sized graphite spheres in a fluidized bed at $985 \mathrm{~K}$ and 20 vol\% $\mathrm{O}_{2}$ has been carried out to i) improve the general understanding of the combustion mechanism, ii) validate the afore reported results of model calculations, iii) examine the predictive strength of the empirical correations for mass and heat transfer coeficients as derived from direct measurements $[2,3]$. Burning rates of individual graphite spheres have been evaluated by IR-analysis of the flue gas (CO and $\mathrm{CO}_{2}$ detection); burning temperatures were additionally recorded in a special series of experiments by connecting the graphite sphere to a thermocouple.

Valuable support for an accurate interpretation of the combustion experiments was provided by a number of specific and separate measurements.

First, the CO conversion over fluidized bed and freeboard has been measured for exactly the same conditions as applied in the graphite sphere combustion experiments and a range of relevant $\mathrm{CO}$ inlet concentrations. The result was used for a correction of the flue gas analysis during graphite sphere combustion, to find the actual primary $\mathrm{CO} / \mathrm{CO}_{2}$ product ratios (Intraparticle and/or boundary layer $\mathrm{CO}$ combustion is unlikely to occur for the the present conditions, see Ref. [1]). Conversion averaged values of the $\mathrm{CO} / \mathrm{CO}_{2}$ ratio appeared to vary between 0.2 and 0.5 for the applied conditions.

A second special measurement was meant to investigate whether the $\mathrm{C} / \mathrm{CO}_{2}$ gasification reaction could possibly contribute to carbon conversion during the combustion experiments. This has been demonstrated to be untrue for the normal FBC situation.

In a third special experiment, the degree of carbon loss due to attrition has been measured by comparing the conversion based on flue gas analysis ( ( $\mathrm{CO}$ and $\mathrm{CO}_{2}$ detection) with the conversion as derived from weight loss determination in a seperate series of graphite combustion experiments. A small discrepancy has been observed at $\mathrm{T}_{\mathrm{b}}=985 \mathrm{~K}$ only.

In the fourth separate experiment, partially combusted graphite spheres of $13 \mathrm{~mm}$ initial diameter have been sphere-symmetrically and layerwise abraded in a special disc-type sander to determine the carbon density profile along the sphere radius. Results of the measurements are given an Figure 5. 


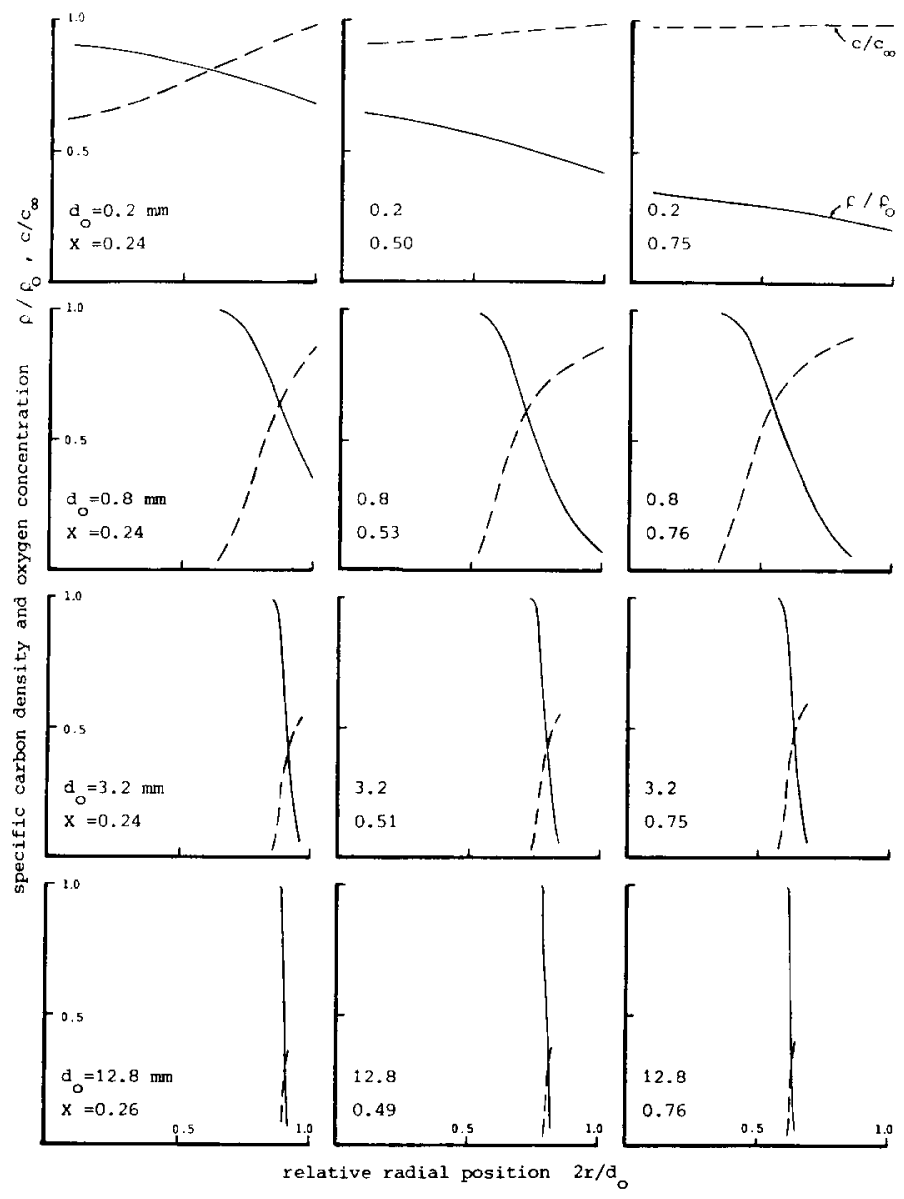

FIGURE 3. Specific intraparticle oxygen concentration (-----) and carton density ( $-(-)$ ) as a function of the relative distance from the burning particle's center in a bed of $669 \mu \mathrm{m}$ alumina particles which is fluidized by a $20 \% \mathrm{O}_{2} / \mathrm{N}_{2}$ gas mixture at $T_{b}=1110 \mathrm{~K}$. Results of ASPC model calculations for the case of primary production of $\mathrm{CO}_{2}$ only $(\Lambda=0.375)$ and four different initial graphite particle diameters. 

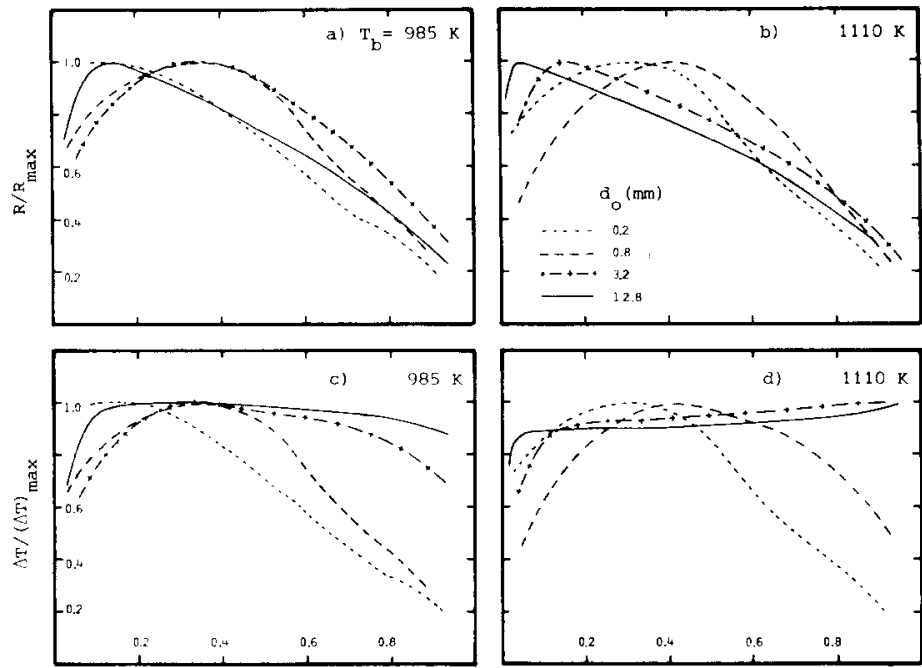

conversion factor $x$

FIGURE 4. Specific combustion rate of graphite spheres ( $a$ and $b$ ), and their corresponding temperature difference with the fluidized bed ( $c$ and $d$ ), as a function of the particle conversion degree. Results of model simulations for the bed temperatures $T_{b}=985$ and $1110 K$, and the conditions mentioned with Figure 1 . Values of $R_{\max }$ and $(\Delta T)_{\max }$ are listed in Table 2 .
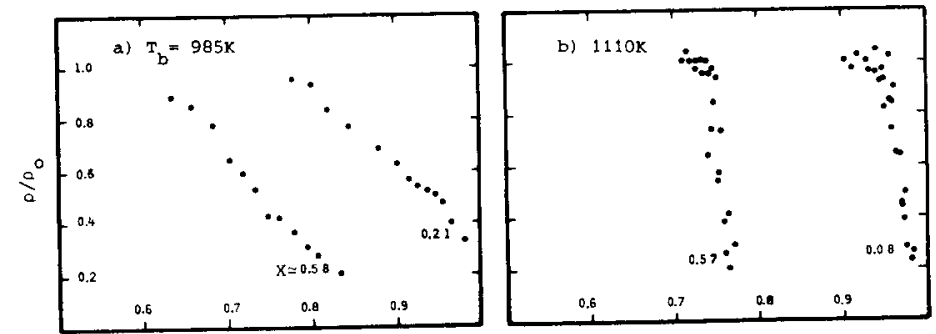

relative radial position $2 x / d$ 。

FIGURE 5. Specific carbon density inside a $13 \mathrm{~mm}$ diameter graphite sphere as a function of the relative distance from the spheres centre. Fluidized bed combustion result obtained for two different temperature and particle conversion levels, and the conditions listed in Table 1.

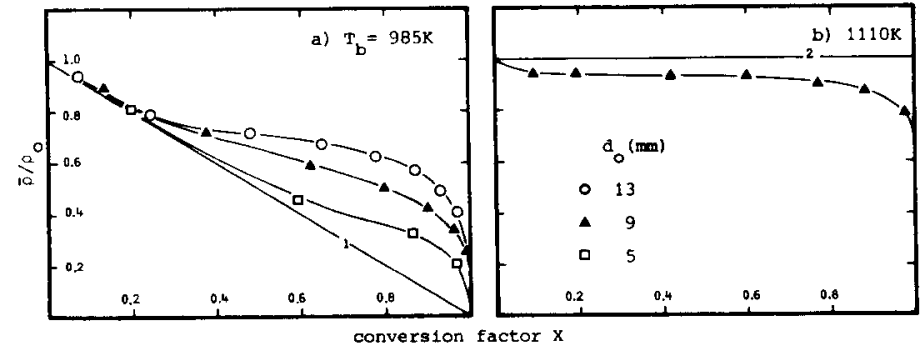

FIGURE 6. Specific average particle density of various sized graphite spheres as a function of their conversion degree. Fluidized bed combustion result for the conditions of Table 1. 1) line of constant particle diameter 2) line of constant particle density. 


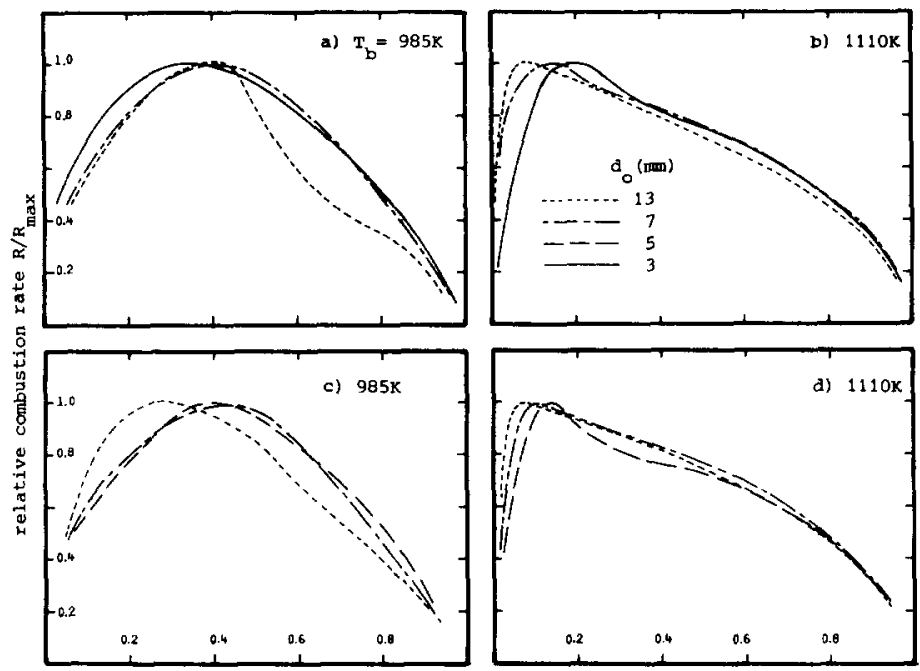

conversion factor $\mathrm{X}$

FIGURE 7. Fluidized bed combustion rate of different sized graphite spheres, relative to the observed maximum value, as a function of their conversion degree. Experimental conditions are given in Table 1 and values for $R_{\max }$ by Table 3 , a) and b): freely moving spheres, c) and d): spheres connected to a thermocouple.

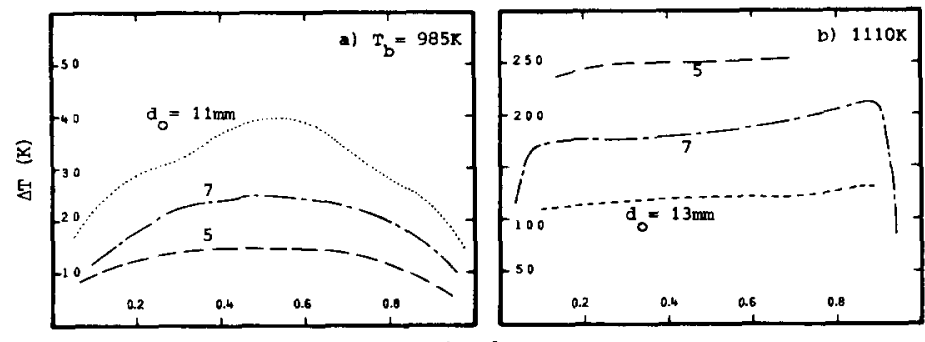

corversion factor $\mathrm{x}$

FIGURE 8. Difference between the burning temperature of various sized graphite spheres and the fluidized bed as a function of the spheres conversion degree. Experimental conditions are given by Table 1.

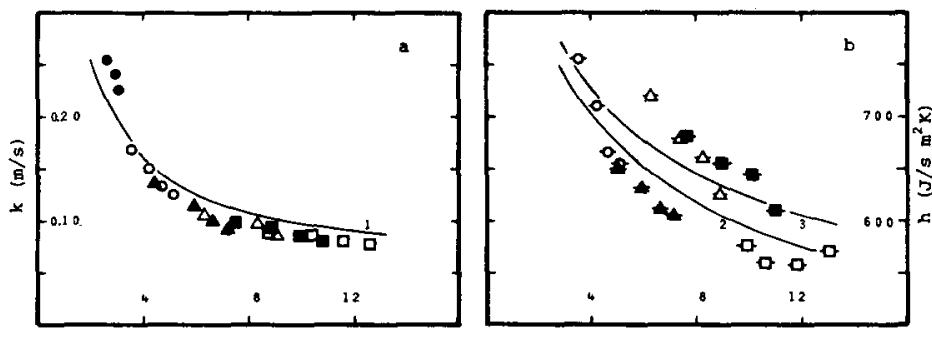

diameter d (mm)

FIGURE 9. Mass (a) and heat (b) transfer coefficients, evaluated from the observed fluidized bed combustion rate and temperature (conditions in Table 1) of graphite spheres, as a function of the sphere diameter. Comparison with values predicted from the empirical correlations of Ref. [2] and [3]. Line 1 and 2: prediction for freely moving spheres, line 3: prediction for fixed spheres. The various symbols refer to the difference in initial sphere diameter; cross- lined symbols are used for spheres connected to a thermocouple. 
They show that oxygen penetrates the graphite sphere over a distance of $1.5 \mathrm{~mm}$ in case of combustion at $\mathrm{T}_{\mathrm{b}}=985 \mathrm{~K}$, while at $\mathrm{T}_{\mathrm{b}}=1110 \mathrm{~K}$ the oxygen penetration depth is only $0.25 \mathrm{~mm}$. Moreover, for such a large carbon particle the extent of oxygen penetration remains essentially constant during combustion, over a relatively long period.

The fifth experiment deals with the density change of burning graphite spheres. Repeated interruption of the single sphere combustion process by nitrogen quenching allows a partially combusted sphere being removed from the fluidized bed for the accurate measurement of its weight and volume. Figure 6 shows that both the graphite sphere density and its diameter are changing during fluidized bed combustion. At $T_{b}=1110 \mathrm{~K}$, however, the $\rho / \rho_{0}$ versus $X$ curves are closer to the constant density line. Evidently, the results of Figures 5 and 6 indicate already that the fluidized bed combustion behaviour at $T_{b}=1110 \mathrm{~K}$ is largely controlled by the transfer of oxygen to (and of heat from) the burning graphite sphere, while at $\mathrm{T}_{b}=985 \mathrm{~K}$ intraparticle transport and the kinetics of the heterogeneous reaction are dominating factors.

The sixth, and last special experiment has been carried out to evaluate the fractional resistance of pore diffusion to the fluidized bed combustion rate at $T_{b}=1110 \mathrm{~K}$. Combustion of various sized graphite spheres has been performed in a conical quartz tube of $200 \mathrm{~mm}$ length and an internal diameter ranging from 7.5 to $17 \mathrm{~mm}$. The tube was fed with a hot $\mathrm{O}_{2} / \mathrm{N}_{2}$ gas mixture of different $\mathrm{O}_{2}$ concentrations, at a flow rate which allowed the sphere to be kept in floating condition without touching the wall. The surface temperature of the burning sphere, which could be varied with the hot gas inlet temperature, was continuously recorded by an optical pyrometer $(950<\mathrm{T}<1010 \mathrm{~K})$. By extrapolating the resulting empirical correlation for the combustion rate $\mathrm{R}^{\prime}$ to the somewhat higher temperature regime of the fluidized bed combustion experiments, the fractional resistance of pore diffusion could be estimated. Combustion rate values observed at $T_{b}=985 \mathrm{~K}$ appeared to be fairly well predicted by the conical tube correlation, which indicated the large extent of pore diffusion control for the entire range of graphite sphere diameters. At $T_{b}=1110 \mathrm{~K}$ however, the fractional resistance of pore diffusion was estimated to decrease from $50 \%$ for the $3 \mathrm{~mm}$, to $10 \%$ for the $13 \mathrm{~mm}$ initial diameter graphite sphere.

Together with Table 3, Figures 7 and 8 report the results of the fluid bed combustion experiments. The observed influence of the particle conversion degree $X$ is in good agreement with the ASPC model predictions. Qualitatively, all the experimental results are in line with the model predictions. However, a substantial quantitative difference emerges which, most probably, is due to the failure of the smooth field assumption (concentration gradients in lateral direction are excluded) implicitly used with the model computations. Besides, it should be noticed that for conditions of external mass transfer control, the burning rate and temperature of a carbon particle fixed to a thermocouple (Figures $7^{\mathrm{d}}$ and $8^{\mathrm{b}}$ ) are always considerably higher than those of a similar but freely moving one, because the rates of mass and heat transfer to/from a fixed sphere are higher (see Ref. [2,3]).

Figure 9 allows the comparison of mass and heat transfer coefficients as predicted by the empirical correlations of Ref. $[2,3]$ with values derived from the results of the present combustion experiments at $\mathrm{T}_{\mathrm{b}}=1110 \mathrm{~K}$. The comparison is accurate because the reaction stoichiometry $\left(\mathrm{CO} / \mathrm{CO}_{2}\right.$ ratio $)$, the degree of pore diffusional limitations, and the burning sphere temperatures, are well-known. In view of the large difference in experimental conditions between the transfer measurements of Ref. [2,3] and the present combustion experiments, the agreement is quite encouraging.

\section{CONCLUSIONS}

Prediction of the carbon particle burning rate and temperature in FBC is well possible if they are governed by physical parameters, determined by the fluidized bed conditions. At normal FBC conditions, that is true for carbon particles larger than approximately 1 (char) to 5 (graphite) millimeter diameter. A shrinking core type model can then be used, but it should include a heat balance and account for the the actual ratio $\mathrm{CO} / \mathrm{CO}_{2}$ produced by the burning particle. In cases where carbon reactivity and intraparticle mass transport play an important role (small carbon particles, low bed temperatures), accurate prediction is difficult. Even such an advanced model as the ASPC model fails to predict the precise combustion rate values. Its usefulness in clarifying the role of intraparticle mass transport phenomena however, has been demonstrated sufficiently. 
NOTATION

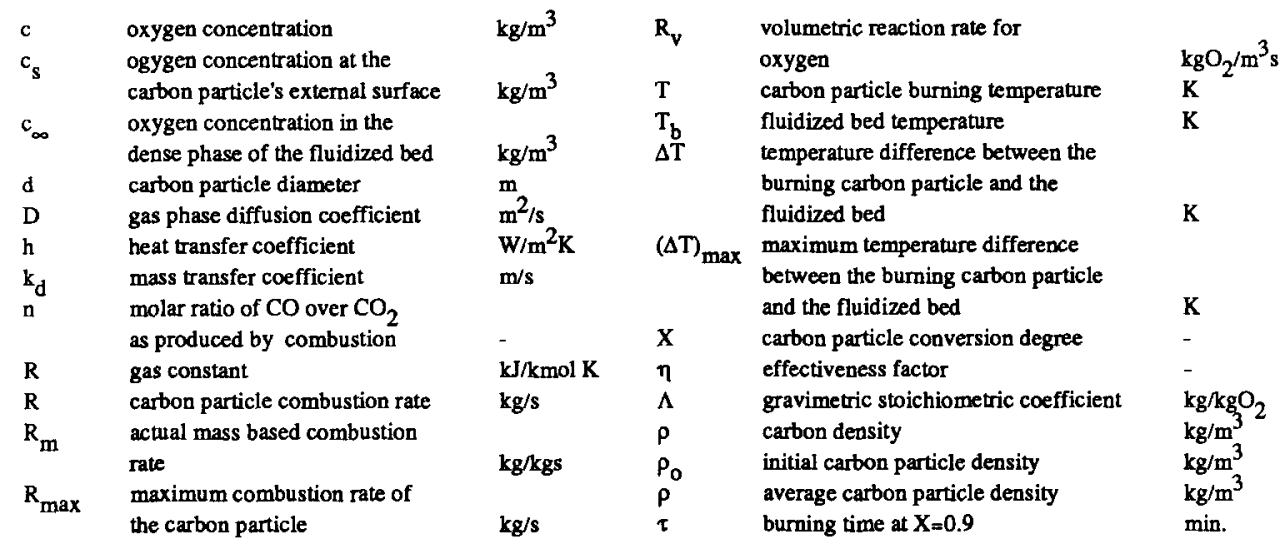

\section{REFERENCES}

1. Prins, W., Fluidized bed combustion of a single carbon particle, Ph. D. thesis (1987), University of Twente, Enschede, The Netherlands, Ch. IV and V.

2. Prins, W., Casteleyn, T.P., Drayer, W. and Van Swaaij, W.P.M., Mass transfer from a freely moving single sphere to the dense phase of a gas fluidized bed of inert particles, Chem. Eng. Sci., vol. 40, pp. 481-495, 1985.

3. Prins, W., Drayer, W. and Van Swaaij, W.P.M., Heat transfer to immersed spheres fixed or freely moving in a gas fluidized bed, Proceedings of the 16th ICHMT Symposium, Dubrovnik 1984, W.P.M. van Swaaij and N.H. Afgan (eds.), Hemisphere Publishing Corporation, Washington DC, USA, pp. 317-331.

4. Szekely, J., Evans, J.W. and Sohn, H.Y., Gas-solid reactions, Academic Press, New York, 1976.

5. Mason, E.A. and Malinauskas, A.P., Gas transport in porous media: the dusty gas model, Chem. Eng. Monograph 17, Elsevier, Amsterdam, 1983.

6. Bliek, A., Mathematical modeling of a cocurrent fixed bed gasifier, Ph. D. thesis (1984), Twente University of Technology, Enschede, the Netherlands. 
Paper: Dr. W. Prins

Question: Prof. K.H. van Heek, Bergbau Forschung GmbH

1. Should the transition from the chemically to the transport controlled regime, you find for the low bed temperature, be ascribed more to mass transfer then to heat transfer limitation?

2. Comment to the contribution of the $\mathrm{C}-\mathrm{CO}_{2}$ reaction. This must be very low at temperatures around $1000 \mathrm{C}$, as the rates of $\mathrm{C}-\mathrm{CO}_{2}$ reactions are far below the rates for the $\mathrm{C}-\mathrm{O}_{2}$ reactions, especially for the very inreactive graphite. However for higher temperatures $(1300 \mathrm{C})$, in the regime of film diffusion control, the $\mathrm{C}-\mathrm{CO}_{2}$ reaction is important, as e.g. already published by $\mathrm{E}$. Wicke et al. 25 years ago.

Answer: Dr. W. Prins, University of Twente

1. The effects of mass and heat transfer limitation cannot easily be separated. They are coupled in the balance between the rate of heat transfer to the fluidized bed and the heat prooduced by the burning particle. A precise answer can only be given after proper model calculations.

Suppose, however, that heat transfer limitation would not occur. Then, the carbon particle burning temperature would always be equal to the fluidized bed temperature and, consequently, the combustion rate be lower than in case an excess-temperature exists. The transition regime II would then be shifted towards a (wider) range of larger carbon particle diameters.

2. Your comment supports my answer to the question raised by Silveston.

Question: Dr. C.M. van den Bleek, Delft Univ. of Technology

Did you also perform the same kind of experiments with a real coal particle to find out whether or not the ASPC model is also valid for a more realistic fuel type.

Answer: Dr. W. Prins, University of Twente

A main objective has been to estimate maximum possible effects of intraparticle mass transport limitations. Graphite was a suitable fuel material in that respect. Coal derived char particles will, to a certain extent, behave similarly. However, the transition from regime III to II and I burning will be shifted towards smaller particle sizes and lower burning temperatures.

The applicability of the ASPC model for char instead of graphite particles has not yet been tested. This will be considered however in current and future studies at the Mech. Eng. Dept. of the Twente University. A relevant article by Brem and Brouwers has recently been accepted for publication in Chemical Engineering Science.

Question: Prof. J. Moulijn, University of Amsterdam.

You used graphite particles as a model material. It is questionable if that is useful. Real coal particles exhibit often swelling behaviour and fragmentation. Moreover, at a 'molecular' scale, coal particles have much more defects and heteroatoms and, as a consequence, are very reactive compared to graphite. Only at high temperatures $(1000 \mathrm{C})$ the structure of coal begins to resemble graphite to a certain extent. Besides, in heat balances, it is important to incorporate a term for ash melting in case of coal.

\section{Answer: Dr. W. Prins, University of Twente}

Coal has no constant properties. Even for a single type, a wide variation in structure and composition is possible. Therefore it will always be difficult to predict accurate burning rate and temperature values for regime $I$ and II conditions. The present study provides a few important conclusions concerning generally possible combustion behavior. In case of regime III combustion, the type of fuel is not important anymore. Combustion behavior is then determined by the fluidized bed hydrodynamics. Swelling and fragmentation belong to the pre-combustion stage. It can affect the understanding of the residual char burning in a sense that the starting conditions are not well-defined. Indeed, in some cases ash melting may affect the burning behavior of a char particle. However since the char particle burning temperatures normally do not reach values over $1050 \mathrm{C}$, this is considered to be quite exceptional.

\section{Question: Prof. P.L. Silveston, University of Waterloo}

1. This deals with your experimental and theoretical conclusion that the $\mathrm{CO}_{2}$ gasification inside the particle is negligible. Is your conclusion limited to the graphite/air system or do you believe it applies to coal combustion as well. Correct theory to my knowledge is that $\mathrm{CO}$ is produced at the carbon particle 
surface by the $\mathrm{C} / \mathrm{CO}_{2}$ gasification reaction. While diffusing away from the particle it reacts with the countercurrently diffusing oxygen. This homogeneous gas phase reaction yields the $\mathrm{CO}_{2}$ which is then consumed at the carbon particle surface.

2. CO oxidation is explicitly neglected in the model. Nevertheless this reaction must occur in your experiments. $\mathrm{CO}$ oxidation reduces the $\mathrm{O}_{2}$ concentration and raises the $\mathrm{CO}_{2}$ concentration on the carbon particle external surface. How is this allowed for in the determination of model parameters and in comparing model with experimental results?

Answer: Dr. W. Prins, University of Twente

Consensus extists in literature that for $\mathrm{FBC}$ conditions, which yield carbon particle burning temperatures around $1000 \mathrm{C}$, the carbon surface is directly attacked by oxygen while both carbon monoxide and carbon dioxide are produced by the heterogeneous combustion reaction.

The double film model which you refer to, is applicable in case of high burning temperatures (1200 C). Although intraparticle and boundary layer oxidation of $\mathrm{CO}$ cannot be excluded, it is not likely to occur at the present temperature level. This has been concluded by combining results of separate experiments, in which the CO conversion over fluid bed and freeboard of the lab-scale unit has been measured, with an analysis of the conditions prevailing inside the particle and its surrounding boundary layer. A literature review and a more extensive discussion is provided by Ref. 1. 